\title{
ASPECTO DO MERCADO MINERÁRIO NOS MUNICÍPIOS ESTANÍFEROS DE RONDÔNIA
}

\section{ARTIGO ORIGINAL}

SOUZA NETO, Antônio Teotônio De ${ }^{1}$

SOUZA NETO, Antônio Teotônio De. Aspecto do mercado minerário nos Municípios Estaníferos de Rondônia. Revista Científica Multidisciplinar Núcleo do Conhecimento. Ano 05, Ed. 10, Vol. 22, pp. 61-77. Outubro de 2020. ISSN: 24480959 , Link de

acesso: https://www.nucleodoconhecimento.com.br/administracao/municipiosestaniferos

\section{RESUMO}

O trabalho intitulado Aspecto do Mercado Minerário nos Municípios Estaníferos de Rondônia, visa demonstrar que os principais municípios produtores de minério de estanho do Estado de Rondônia: Ariquemes, Campo Novo, Itapuã do Oeste, Monte Negro e Porto Velho, produzem minérios que alcançam diversos centros consumidores, pois diferentes substâncias minerais exploradas nessas municipalidades, interagindo assim com o mercado local do Estado de Rondônia, interno brasileiro e externo. Dessa forma buscou-se elucidar o questionamento: qual o comportamento do setor de mineração nos municípios estaníferos de Rondônia? Objetivou-se pesquisar que substâncias minerais são produzidas nos municípios estaníferos de Rondônia e que mercados são abastecidos por esses minérios, como também a geração de emprego em decorrência da atividade de mineração e o comportamento da arrecadação da Compensação Financeira pela Exploração de

\footnotetext{
${ }^{1}$ Doutor em Administração pela Universidade Nacional de Rosário - UNR - Argentina; Especialista em Recursos em Minerais/Economista da Agência Nacional de Mineração; Especialista em Gestão e Legislação Tributária; Bacharel em Ciências Econômicas.
} 
Recursos Minerais. Utilizou-se a metodologia com enfoque qualitativo e o estudo descritivo, foi uma pesquisa bibliográfica. Os instrumentos de coleta de dados foram: livros, revistas, sites da internet, artigos e a legislação correlata. A investigação demonstrou que as substâncias minerais extraídas nos municípios de Ariquemes, Campo Novo, Itapuã do Oeste, Monte Negro e Porto Velho, atingem diversos centros consumidores; que a Compensação Financeira pela Exploração de Recursos Minerais é empregada pelo poder público como forma de compensar os Estados e Municípios pelos danos ambientais e sociais ocasionados pela exploração mineral; que a indústria de mineração é uma importante fonte de emprego e utiliza uma parcela considerável da população economicamente ativa dos municípios pesquisados; os mineradores que organizaram profissionalmente suas empresas aplicam técnicas empresariais e planejamento para desenvolvimento no médio e longo prazo.

Palavras-chave: Mercado, mineração, substância.

\section{INTRODUÇÃO}

O presente trabalho aborda que se iniciou a mineração na área do Estado de Rondônia no século XVII, por desbravadores que tinham o objetivo de aprisionar índios da região para o trabalho escravo, como também intencionados em encontrar ouro.

Demonstra que objetivando equilibrar a balança comercial brasileira, onde o estanho era importado para atender a demanda da indústria nacional, foram adotadas duas medidas legais importantes para o então Território Federal de Rondônia, a criação em 1969 da Delegacia Especial do Departamento Nacional de Produção Mineral e da área denominada Província Estanífera de Rondônia.

Explana que os recursos minerais, inclusive os do subsolo, são bens da União que transfere o direito de explorar para terceiros, em consequência da exploração dos minérios para fins de aproveitamento econômico é arrecadada a Compensação Financeira pela Exploração de Recursos Minerais. 
Descreve ainda, o setor de mineração nos municípios de Ariquemes, Campo Novo de Rondônia, Itapuã do Oeste, Monte Negro e Porto Velho, demonstra o número de empresas existentes na atividade mineral, a geração de emprego em decorrência da mineração, os minérios produzidos, o mercado consumidor e o comportamento do mercado.

\section{MINERAÇÃO NO ESTADO DE RONDÔNIA}

O Estado de Rondônia começa a se configurar em 13 de setembro de 1943, Getúlio Vargas presidente da República à época através do Decreto-Lei 5.812, intencionado em propiciar mais segurança às fronteiras nacionais cria cinco territórios federais, entre eles o do Guaporé.

Em homenagem ao militar sertanista Marechal Cândido Mariano da Silva Rondon, o presidente Juscelino Kubitschek de Oliveira muda o nome de Território Federal do Guaporé para Território Federal de Rondônia através da Lei 2.731, em 17 de fevereiro de 1956.

O atual Estado de Rondônia foi instituído pelo presidente da República João Baptista Figueiredo em 22 de dezembro de 1981 através da Lei Complementar 041, vindo a ser constituído em 4 de janeiro de 1982, contava na época com treze municípios.

Rondônia localiza-se na Região Norte, tem uma área de $237.765,240 \mathrm{Km}^{2}$, sua capital é Porto velho, apresenta uma população estimada em 2020 de 1.796 .460 pessoas, com uma Densidade demográfica 6,58 hab/ $\mathrm{km}^{2}$ (ano de 2010), índice de desenvolvimento humano - IDH é de 0,690 (ano de 2010) dados do IBGE, atualmente está dividido em 52 municípios, conforme mapa geopolítico abaixo. 


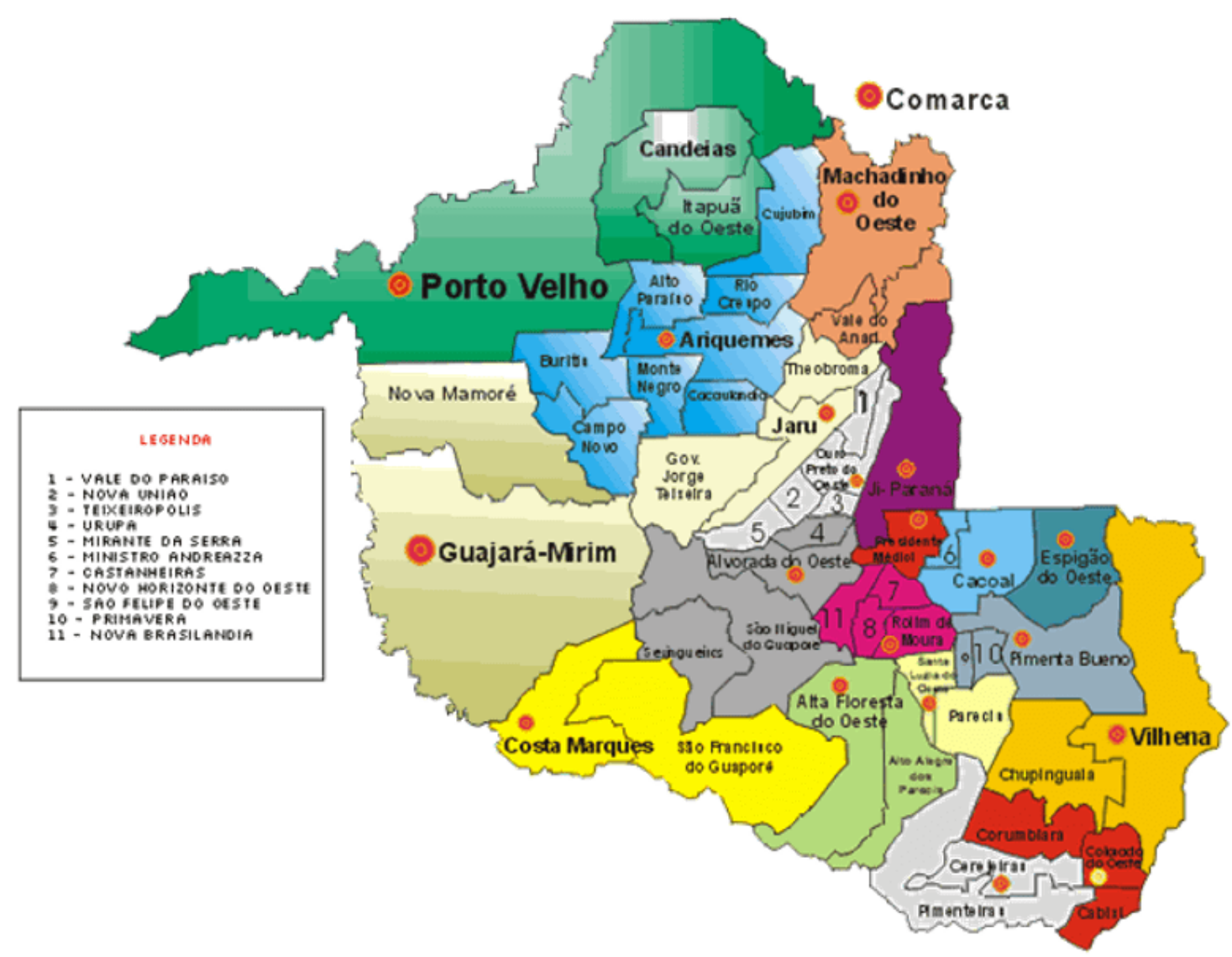

Fonte: Núcleo de Tecnologia Educacional de Ji-paraná

É imprescindível destacar, que a mineração na área do Estado de Rondônia começa no século XVII, por desbravadores com a intenção de aprisionar índios da região para o trabalho escravo, como também com o intuito encontrar ouro, no entanto, para Oliveira (2004, p. 71), "a verdadeira corrida do ouro iniciou-se nos idos de 1978 , momento em que ocorre a substituição da extração rudimentar pela mecanizada".

O minério de estanho foi descoberto em 1952, segundo Oliveira (2004, p. 68), "um teor elevadíssimo, $5 \mathrm{Kg}$ de $\mathrm{SnO} 2 / \mathrm{m}^{3}$. Comparando com o da Malásia (área de maior produção até então), cujo teor era de $0,350 \mathrm{Kg}$ de $\mathrm{SnO} 2 / \mathrm{m}^{3 "}$, com a exploração deste minério houve uma intensa migração para a região.

Algumas medidas legais foram tomadas no intuito de equilibrar a balança comercial brasileira, onde o estanho era importado para atender a demanda da indústria nacional, foi então criado em 1969 a Delegacia Especial do DNPM, como também a 
Província Estanífera de Rondônia, de acordo com Carvalho Neto (2004, p. 6), "área de abrangência da denominada Província Estanífera de Rondônia que abrangia todo o então Território Federal de Rondônia, e partes dos estados de Mato Grosso e Amazonas".

O Estado de Rondônia posiciona-se como fronteira de desenvolvimento, principalmente no setor mineral, oferecendo uma boa diversidade de substâncias, tais como os minerais metálicos: Cassiterita, Chumbo, Columbita, Ouro, Manganês, Tantalita, Wolframita e Zinco. Não metálicos: Areia, Argilas Comuns, Calcário (Rochas), Cascalho, Diamante, Gemas, Rochas (Britadas) e Rochas Ornamentais (Granito e afins), além de Água Mineral.

A Cassiterita (minério de estanho) é o principal minério de Rondônia, ocorrendo com maior frequência nos municípios de Ariquemes, Campo Novo, Itapuã do Oeste, Monte Negro, Porto Velho e Rio Crespo. O estado ocupa atualmente a segunda colocação nacional na produção deste minério.

O valor arrecadado no Estado de Rondônia com a Compensação Financeira pela Exploração de Recursos Minerais, no período de 2015 a 2019, seguiu uma trajetória de crescimento de 2015 a 2018, havendo uma queda em 2019 de 17,7\% em relação ao ano de 2018, conforme o gráfico abaixo.

Gráfico 1 - Arrecadação de CFEM em Rondônia

\section{Arrecadação de CFEM em Rondônia de 2015 a 2019}
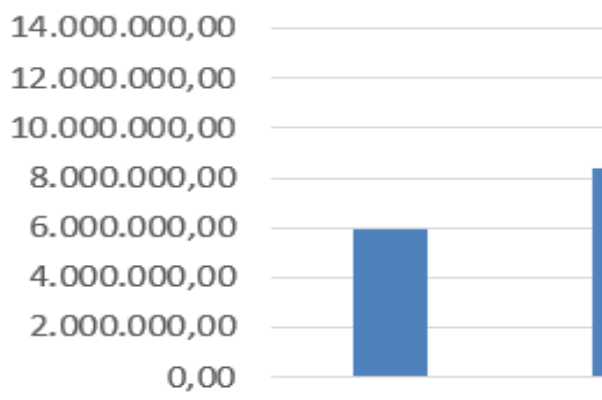

2015

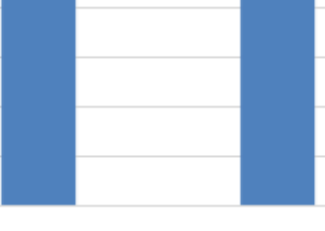

2017

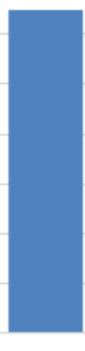

2018

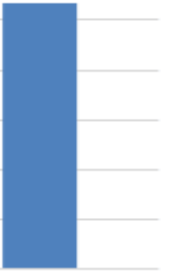

2019

Fonte: Autor 
Tabela 1 - Arrecadação de CFEM em Rondônia

\begin{tabular}{|l|r|}
\hline Ano & \multicolumn{1}{|l|}{ CFEM } \\
\hline $\mathbf{2 0 1 5}$ & $5.906 .137,42$ \\
\hline $\mathbf{2 0 1 6}$ & $8.396 .501,60$ \\
\hline $\mathbf{2 0 1 7}$ & $10.489 .699,64$ \\
\hline $\mathbf{2 0 1 8}$ & $12.961 .032,20$ \\
\hline $\mathbf{2 0 1 9}$ & $10.665 .987,43$ \\
\hline Fonte: Dados da ANM & \\
\hline
\end{tabular}

Verificou-se o crescimento positivo no período de quatro anos na arrecadação da Compensação Financeira pela Exploração de Recursos Minerais e um recuo em 2019, frustrando assim a trajetória de crescimento.

\subsection{MERCADO MINERÁRIO DOS MUNICÍPIOS ESTANÍFEROS DE RONDÔNIA}

Analisando-se os principais municípios produtores de minério de estanho do Estado de Rondônia: Ariquemes, Campo Novo, Itapuã do Oeste, Monte Negro e Porto Velho, constata-se que alcançam diversos centros consumidores, pois são diferentes substâncias minerais exploradas nessas municipalidades, interagindo assim com o mercado local do Estado de Rondônia, interno brasileiro e externo, segundo Pindyck e Rubinfeld, (2006, p. 7), "Um mercado é, pois, um grupo de compradores e vendedores que, por meio de suas reais ou potenciais interações, determinam o preço do produto ou de um conjunto de produtos."

No entanto, verifica-se de que vários conceitos de mercado são plausíveis, porém Galbaith considerou uma definição mais ampla, a qual foi citada por Rossetti.

Mercado, agora, é uma abstração. Já não existe a conotação geográfica. Executivos de grandes empresas industriais ou do setor financeiro falam das dificuldades com que eles se defrontam no Mercado. E eles não estão se referindo a nenhum lugar, mais a uma abstração econômica (ROSSETTI, 2001, p. 395). 
De acordo com Pindyck e Rubinfeld (2006), no mercado podem-se dividir as unidades econômicas individuais em dois grandes grupos levando-se em consideração a função: compradores e vendedores. Do lado dos compradores estão os demandantes dos bens minerais e as empresas que absorvem mão-de-obra, capital e matérias primas para beneficiamento dos minérios. Do lado dos vendedores estão às empresas que ofertam as substâncias minerais, os trabalhadores que ofertam sua mão-de-obra e os comerciantes que oferecem as matérias primas para beneficiamento dos minérios.

Para abordar as interações dos mercados em que estão envolvidos os minérios explorados nos municípios unidades de análise dessa pesquisa, necessário se faz realizar o diagnóstico do número de empresas que compõe o setor, mão-de-obra envolvida no processo de explotação e a destinação dos produtos Minerários.

\subsection{SETOR MINERÁRIO DOS MUNICÍPIOS ESTANÍFERO DE RONDÔNIA}

Setor é, pois, o conjunto de empresas que ofertam os produtos em um mercado de determinado produto ou de produtos correspondentes. No caso do estudo em pauta, o setor é constituído por empresas e pessoas físicas detentoras dos títulos de direitos minerários para exploração dos recursos advindos da mineração em cinco municípios, havendo um forte domínio das empresas extratoras de minério de estanho.

No Estado de Rondônia Ariquemes se destaca no seguimento de produtos metálicos, pois nessa municipalidade estão localizadas as empresas de fundição que são responsáveis pela transformação da cassiterita em estanho, o município hoje é o polo de estanho do Estado e do Brasil.

Existem 126 empresas na atividade de extração mineral nos municípios objeto da pesquisa, sendo que Ariquemes concentra o maior número delas, pois reúne 60 estabelecimentos, em seguida vem Porto Velho com 59 empresas, dados do CAGED (2020). 
Os recursos minerais, inclusive os do subsolo, são bens da União que através de Concessão, Permissão, Autorização e Licenciamento, transfere a terceiros o direito de explorar, em decorrência da exploração dos minérios para fins de aproveitamento econômico é cobrada a Compensação Financeira pela Exploração de Recursos Minerais - CFEM. Cabendo a Agência Nacional de Mineração - ANM, autarquia federal vinculada ao Ministério de Minas e Energia baixar normas e exercer fiscalização, como também aplicar penalidades.

A CFEM é utilizada como forma compensar os Estados e Municípios pelos impactos ambientais e sociais ocorridos pela exploração mineral no âmbito dos seus territórios, sendo distribuída: $60 \%$ para o Município de origem da produção; $15 \%$ para o Estado onde ocorrer a produção; $15 \%$ para Municípios afetados pela atividade de mineração e a produção; 10\% para Órgãos da União. O quadro abaixo apresenta um panorama da arrecadação de CFEM nos municípios.

Tabela 2 - ARRECADAÇÃO DE CFEM NOS MUNICÍPIOS

\begin{tabular}{|l|l|l|l|l|l|}
\hline \multicolumn{6}{|l}{ Arrecadação de CFEM nos Municípios } \\
\hline Município & Ariquemes & $\begin{array}{l}\text { Campo } \\
\text { Novo }\end{array}$ & $\begin{array}{l}\text { Itapuã } \\
\text { Oeste }\end{array}$ & $\begin{array}{l}\text { Monte } \\
\text { Negro }\end{array}$ & Porto Velho \\
\hline 2015 & $\mathbf{9 4 2 . 5 4 5 , 3 7}$ & $\mathbf{1 . 3 9 8 . 3 9 2 , 7 3}$ & $\mathbf{4 6 1 . 8 9 1 , 0 6}$ & $\mathbf{0}$ & $\mathbf{1 . 3 6 8 . 6 2 6 , 0 5}$ \\
\hline 2016 & $2.657 .113,28$ & $1.512 .146,08$ & $300.671,94$ & 0 & $1.546 .825,17$ \\
\hline 2017 & $3.128 .924,78$ & $1.465 .058,44$ & $244.879,07$ & 0 & $1.368 .522,49$ \\
\hline 2018 & $3.351 .701,73$ & $1.503 .275,33$ & $1.498 .777,33$ & 0 & $2.317 .311,51$ \\
\hline 2019 & $3.470 .893,31$ & $\mathbf{9 3 7 . 0 5 0 , 3 9}$ & $\mathbf{7 9 8 . 9 6 2 , 5 0}$ & $\mathbf{0}$ & $\mathbf{2 . 9 8 1 . 4 9 5 , 5 3}$ \\
\hline
\end{tabular}

Fonte: Dados da ANM

A arrecadação da Compensação Financeira pela Exploração de Recursos Minerais no município de Ariquemes seguiu uma trajetória de crescimento em todos os anos de 2015 a 2019, conforme gráfico abaixo. 
Gráfico 2 - Arrecadação de CFEM em Ariquemes

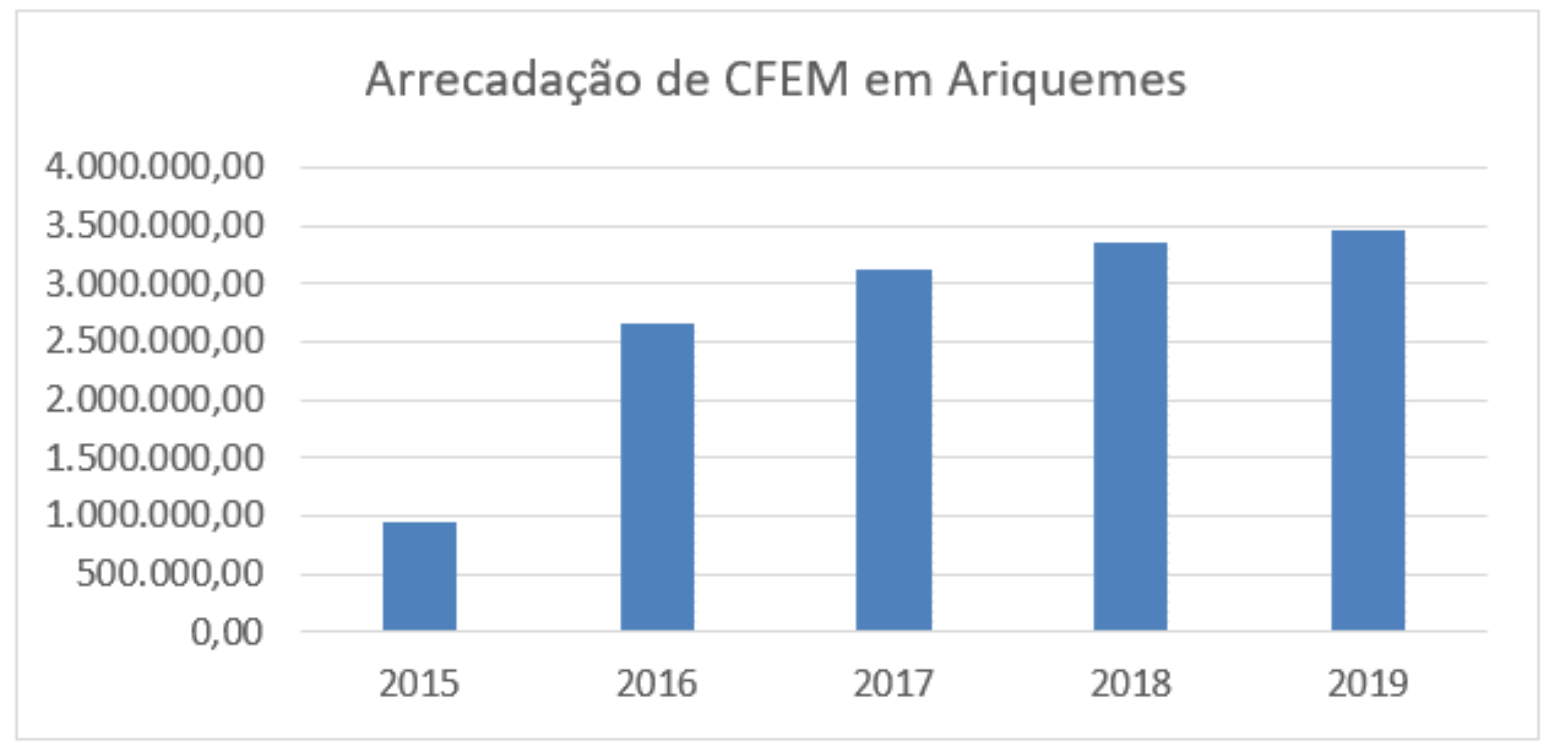

Fonte: Autor

No município de Campo Novo de Rondônia ocorreu oscilação na arrecadação de CFEM no período estudado, com aumento em 2016 e recuo em 2017, a mesma instabilidade aconteceu nos anos seguintes com crescimento em 2018 e recuo em 2019, conforme gráfico abaixo.

Gráfico 3 - Arrecadação de CFEM em Campo Novo de Rondônia

\section{Arrecadação de CFEM de Campo Novo de Rondônia}
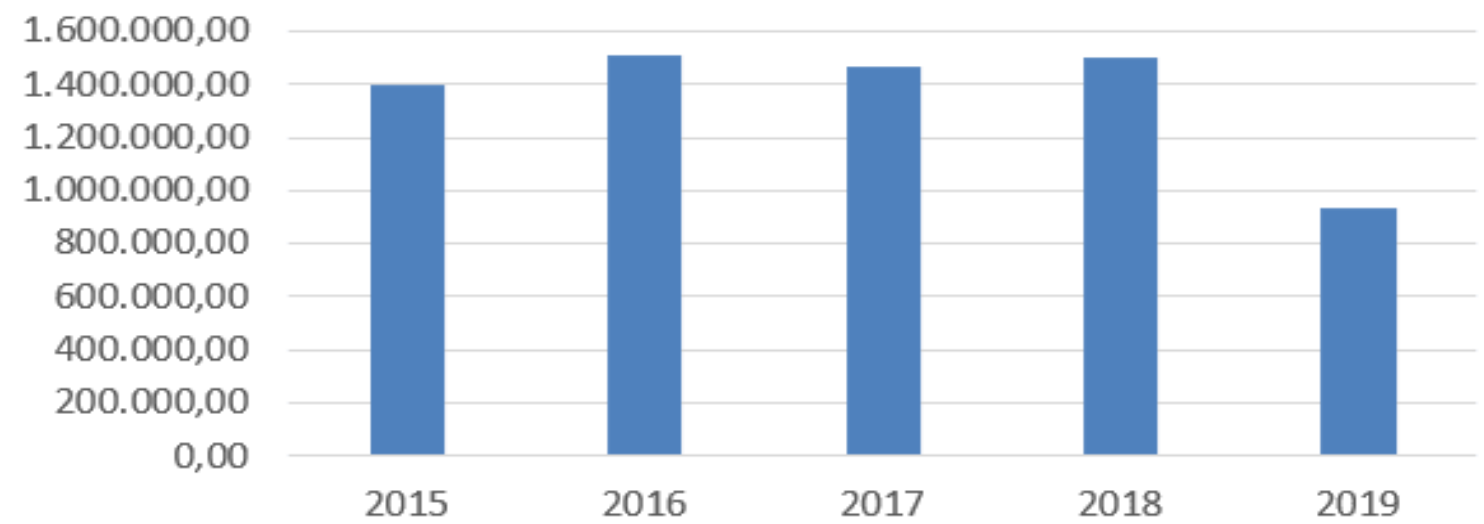

2015

2017

2018

2019

Fonte: ANM

RC: 63213

Disponível em: https://www.nucleodoconhecimento.com.br/administracao/municipios-estaniferos 
O município de Itapuã do Oeste seguiu uma trajetória de recuo na arrecadação de CFEM nos anos pesquisados, com exceção de 2018, analisando-se sempre em relação ao ano anterior, conforme gráfico abaixo.

Gráfico 4 - Arrecadação de CFEM em Itapuã do Oeste

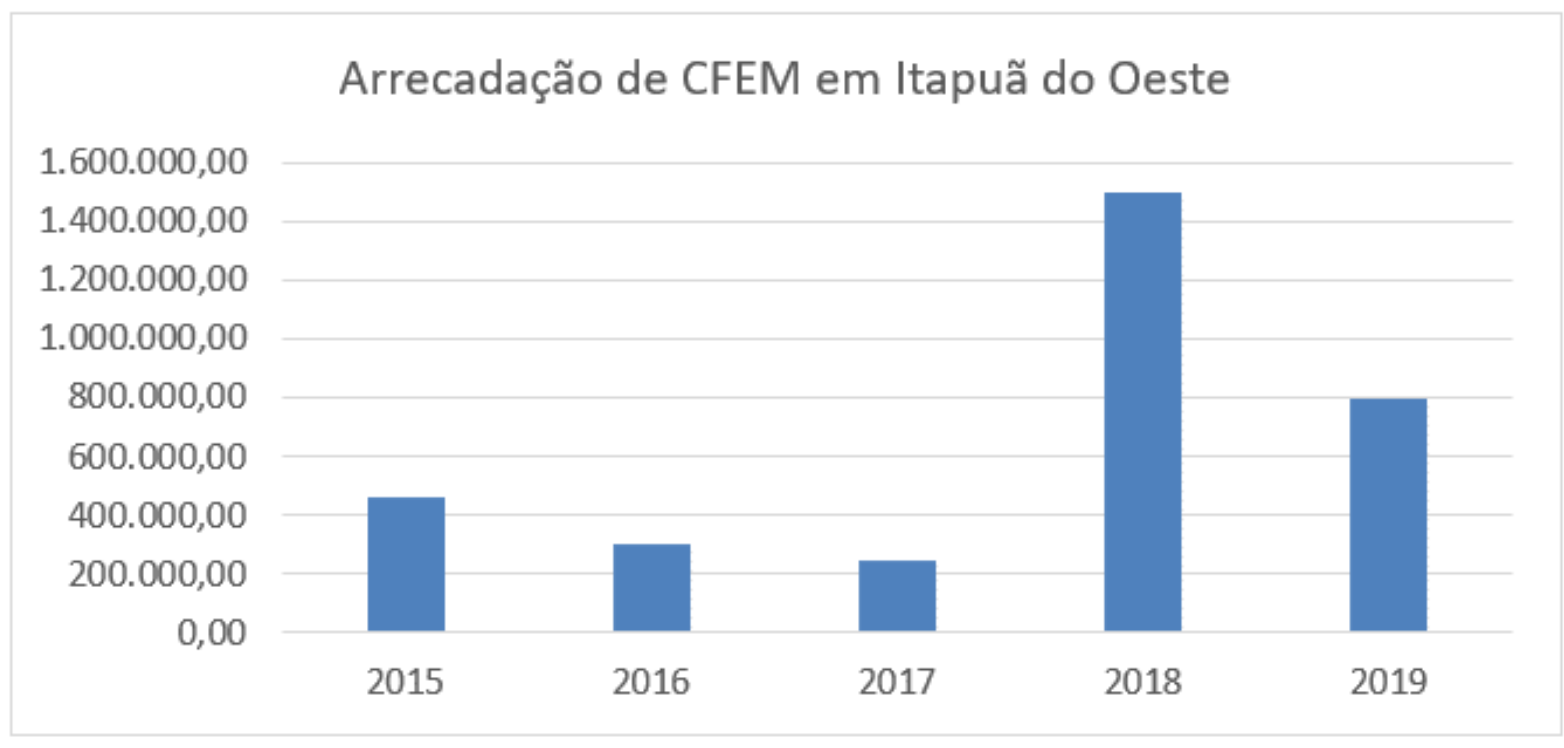

Fonte: Autor

No estudo efetuado com relação à receita da CFEM no município de Monte Negro, verificou-se que não houve arrecadação da Compensação Financeira pela Exploração de Recursos Minerais, sendo imprescindível que se institua para ANM aparatos eficientes para aplicação de penalidades visando inibir a sonegação dos royalties da mineração, de modo que as riquezas minerais possam ser geridas com o máximo de sustentabilidade e estas receitas possam ser utilizadas em prol das comunidades afetadas pelas externalidades negativas advindas da exploração mineral.

A Compensação Financeira pela Exploração de Recursos Minerais, arrecadada no município de Porto Velho seguiu uma trajetória de crescimento, com exceção apenas do ano de 2017 onde ocorreu uma diminuição em relação a 2016, voltando a crescer em 2018 e 2019, conforme gráfico abaixo. 
Gráfico 5 - Arrecadação de CFEM em Porto Velho

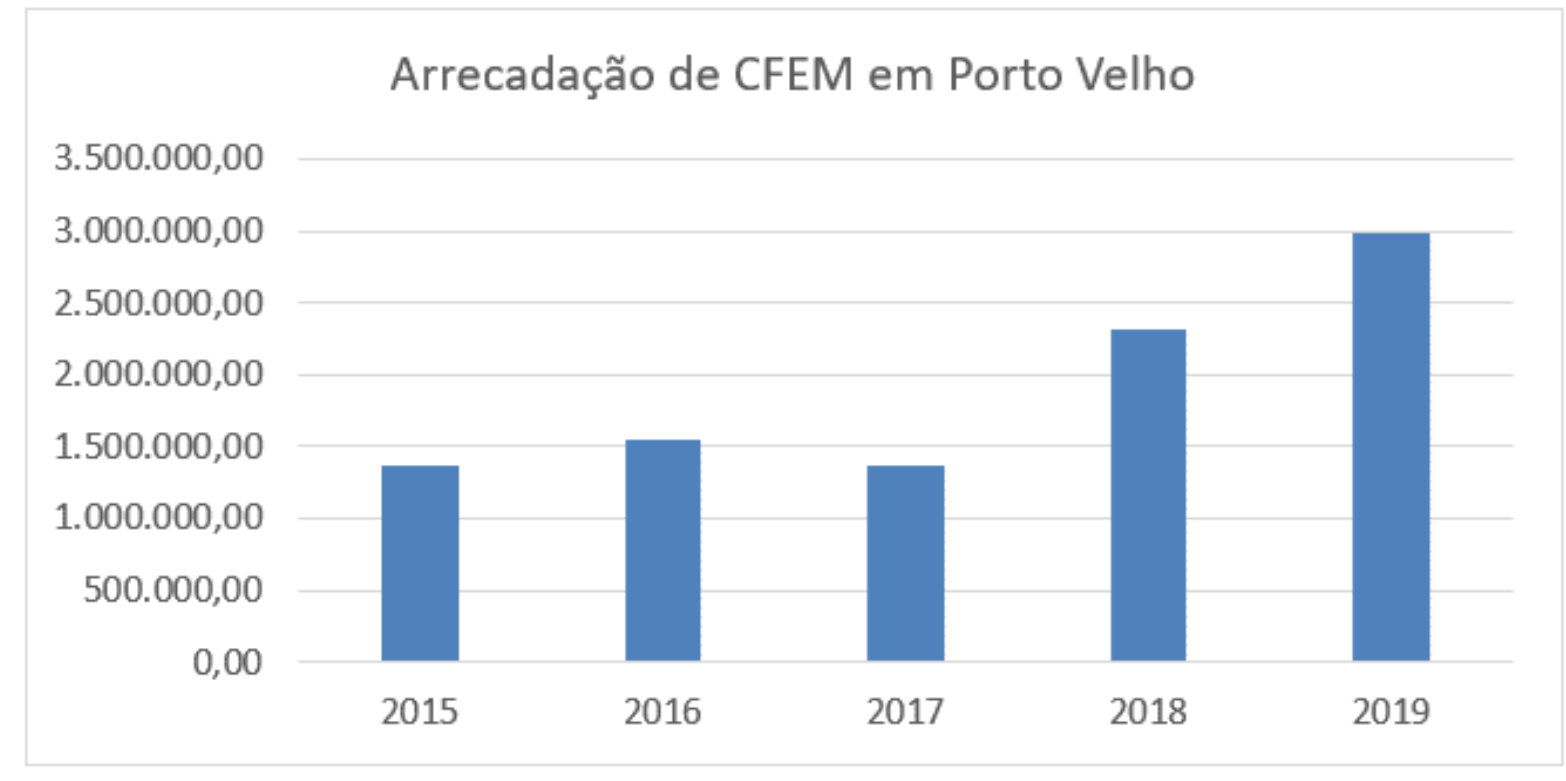

Fonte: Autor

O resultado da produção de substâncias minerais nos municípios de Ariquemes, Campo Novo de Rondônia, Itapuã do Oeste, Monte Negro e Porto Velho, tendo como parâmetro o Produto Interno Bruto de cada municipalidade, apresenta-se com maior importância em Campo Novo de Rondônia onde os valores de vendas dos minérios perfazem 43,95 por cento do PIB municipal. Em seguida vem Itapuã do Oeste onde a relação produção mineral/PIB é de 26,66 por cento, o município de Porto Velho é o que apresenta o menor índice com apenas 0,09 por cento, conforme tabela abaixo.

Tabela 3 - Relação Entre Produto Interno Bruto E Produto Da Mineração - Ano 2017

\begin{tabular}{|l|l|l|l|l|l|}
\hline \multicolumn{5}{|c|}{ Relação entre Produto Interno Bruto e Produção da Mineração - Em R\$ 1000} \\
\hline Município & Ariquemes & $\begin{array}{l}\text { Campo } \\
\text { Novo }\end{array}$ & $\begin{array}{l}\text { Itapuã do } \\
\text { Oeste }\end{array}$ & $\begin{array}{l}\text { Monte } \\
\text { Negro }\end{array}$ & Porto Velho \\
\hline PIB & $\mathbf{2 . 2 9 6 . 0 7 3 , 7 1}$ & $\mathbf{2 7 6 . 5 3 1 , 8 5}$ & $\mathbf{1 6 0 . 8 2 7 , 5 1}$ & $\mathbf{2 6 8 . 2 5 8 , 1 4}$ & $\mathbf{1 6 . 5 1 4 . 5 3 5 , 2 0}$ \\
\hline $\begin{array}{l}\text { Produção } \\
\text { da }\end{array}$ & $\mathbf{1 3 8 . 9 1 4 , 2 2}$ & $\mathbf{1 2 1 . 5 2 5 , 3 5}$ & $\mathbf{4 2 . 8 7 1 , 4 4}$ & $\mathbf{1 4 . 8 4 7 , 9 8}$ & $\mathbf{1 4 9 . 4 0 1 , 2 2}$ \\
\hline \begin{tabular}{l} 
Mineração \\
\hline
\end{tabular} & & & & & \\
\hline
\end{tabular}




\begin{tabular}{|l|l|l|l|l|l|}
\hline Relação & 0,0605 & 0,4395 & 0,2666 & 0,0553 & 0,0090 \\
\hline$\%$ & 6,05 & 43,95 & 26,66 & 5,53 & 0,09 \\
\hline
\end{tabular}

Fonte: Autor

O montante da produção mineral de cada município foi extraído dos Relatórios Anuais de Lavra do ano base 2017, sendo estes atos declaratórios dos mineradores para Agência Nacional de Mineração, e o Produto Interno Bruto de 2017 das municipalidades obtidos do IBGE.

\subsection{EMPREGO}

Emprego é um vínculo ao qual o trabalhador está ligado para satisfazer as suas necessidades financeiras, não se relacionando ao bem-estar pessoal, que pode ou não ser proporcionado pelo desempenho da atividade que a pessoa está executando no setor econômico em que atua.

A população Economicamente Ativa é composta pelos indivíduos que estão inseridos no mercado de trabalho, ou ofertando sua força laboral com a finalidade de se encaixar em uma atividade remunerada, segundo Rosseti:

A população economicamente ativa constitui-se por empregadores, empregados e autônomos (que trabalham por conta própria). A aptidão e a capacitação para o exercício de atividades produtivas são definidas por parâmetros como herança cultural, grau de instrução e sanidade física e mental. Este subconjunto, em relação ao contingente economicamente mobilizável varia em função de fatores sazonais e conjunturais (ROSSETI, 2002, p.103).

A indústria de mineração é uma importante fonte de emprego, absorve uma boa parcela da população economicamente ativa nos municípios estaníferos de Rondônia, em 2019 foi responsável pelo emprego formal direto de 843 pessoas, segundo dados do Cadastro Geral de Empregados e Desempregados - CAGED, no entanto esse número passa a ser bem mais expressivo quando as fontes utilizadas são os Relatórios Anuais de Lavra - RAL, totalizando-se 2384 pessoas ocupadas na mineração, conforme a tabela abaixo. 
Tabela 4 - Tabela Comparativa Entre Empregos Formais E Declarados No RAL

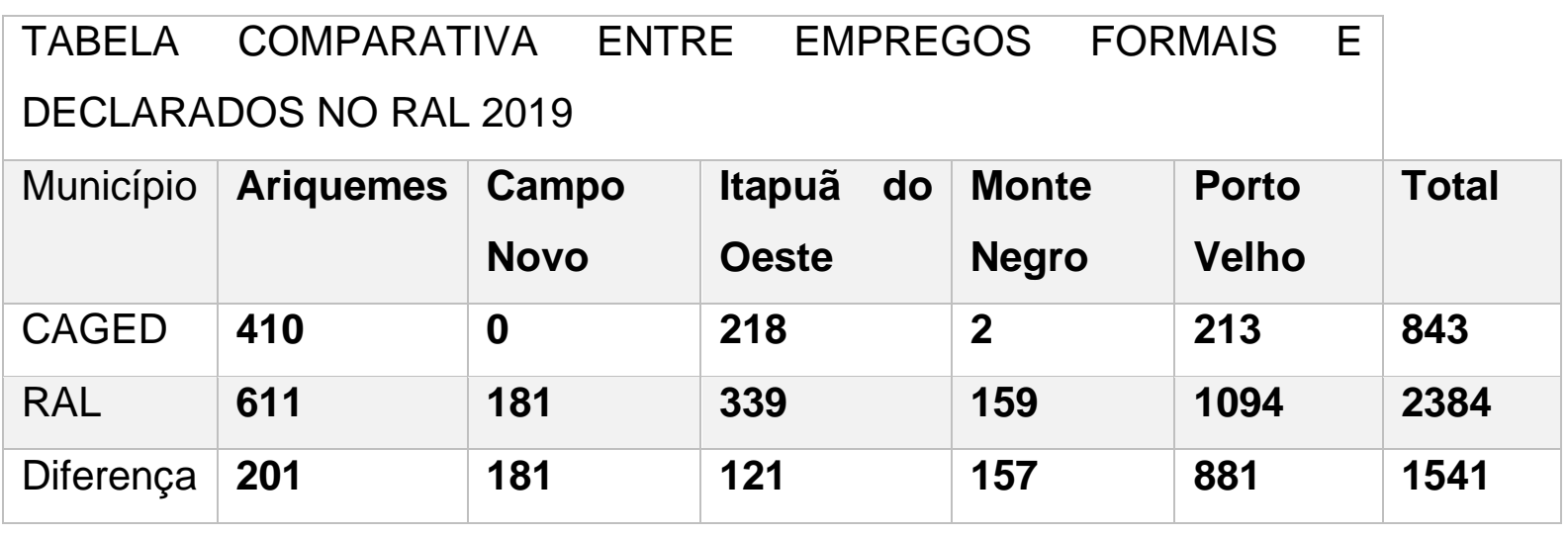

Fontes: RAL; CAGED.

Essa discrepância explica-se no fato de que os dados apresentados pelo CAGED, são relativos aos empregos formais que consistem em atividades com carteira profissional assinada, e nos números declarados nos RAL's estão agregados os empregos formais, empregados de empresas terceirizadas e cooperativados.

\subsection{MERCADO CONSUMIDOR}

O consumo é determinado em função de duas variáveis principais o quanto se deseja adquirir e os preços dos bens, pelo pensamento econômico clássico no comportamento do consumidor as variáveis, preço e quantidade, correlacionam-se inversamente. Contudo cada indivíduo apresenta um comportamento diferente de acordo com a sua necessidade pelo bem e a disponibilidade financeira, no entanto a soma do comportamento de todos, agregando-se os números acaba prevalecendo a correlação inversa, ou seja, quando os preços estão baixos aumenta as quantidades demandadas, de acordo com Rosseti (2002, p.410), "A procura de determinado produto é determinada pelas várias quantidades que os consumidores estão dispostos e aptos a adquirir, em função de vários níveis possíveis de preços em dado período de tempo".

Os preços dos minérios levam em consideração os custos de extração, oferta e a demanda pela substância mineral, muitos deles são materiais cotados 
como commodities e o preço é determinado pelo mercado mundial, sendo assim as mineradoras que participam do mercado de commodities dispõem de pouco ou nenhum poder para comercializar por valores diferentes.

As substâncias minerais mais consumidas em todo mundo são os agregados minerais usados na construção civil: areia, argila, cascalho e pedra britada, devido ao baixo valor unitário e a disponibilidade existente na natureza são comercializados no mercado local de Rondônia, no entanto a brita produzida em Porto velho tem consumo também nos Estados do Acre e Amazonas.

A columbita é muito valorizada tendo em sua composição: tântalo que é utilizado na indústria eletrônica, vidro e aço cirúrgico, e o nióbio que é usado em ligas de alta resistência e vários materiais supercondutores, sendo comercializada no mercado externo principalmente para Alemanha e China.

A cassiterita o principal minério explorado no Estado de Rondônia tem como principais compradores as fundições de metais não ferrosos: White Solder, Melt Metais, Coopermetal, CFC da Amazônia e Estanho de Rondônia. Após o processo de transformação o Estanho é comercializado no mercado interno brasileiro e externo. No entanto é vendida também como minério antes do processo industrial para o mercado interno brasileiro e para o exterior.

O minério de ouro extraído no leito do Rio Madeira em Porto Velho tem como principais produtores as cooperativas: COOGARIMA, MINACOOP e COOGAM. Tendo como principais compradores as Distribuidoras de Títulos e Valores Mobiliários - DTVM's instaladas na capital do Estado, em seguida o metal é transferido para as Matrizes em São Paulo.

\subsection{COMPORTAMENTO DO MERCADO}

O principal minério explorado no âmbito dos municípios estaníferos de Rondônia como o próprio nome propõe é o minério de estanho (cassiterita), o funcionamento deste 
mercado no Estado tem como centro o município de Ariquemes, onde a substância mineral tem como principais compradores as empresas fundidoras.

O preço do minério de estanho em Ariquemes é formado, levando-se em consideração o preço do estanho no London Metal Exchange - LME, cotação do dólar e o teor de estanho contido, conclui-se retirando de 13 a $15 \%$ do montante referente ao custo de processamento.

A cassiterita depois de transformada em estanho pelas empresas de fundição abastece o mercado interno Brasileiro e o mercado mundial, o preço é cotado pela LME que é a bolsa de metais de Londres. O estanho faz parte de um mercado bastante competitivo, segundo Pindyck e Rubinfeld:

O mercado mundial de cobre contém algumas dezenas de produtores importantes. Entretanto, esse número já é suficiente para que o impacto no preço seja insignificante caso algum dos produtores venha a encerrar suas atividades. O mesmo ocorre com muitos outros mercados de recursos minerais e naturais, tais como carvão, ferro, estanho ou madeira (PINDYCK e RUBINFELD, 2006, p.7)

As substâncias minerais produzidas nos municípios estaníferos de Rondônia são água mineral, areia, argila, cascalho, cassiterita, columbita, gemas, ilmenita, ouro e pedra britada, a tabela abaixo apresenta um mapeamento das substâncias relacionando-as ao mercado onde são comercializadas. 
Tabela 5 -Substância Mineral Relacionada A Comercialização

\begin{tabular}{|l|l|l|l|}
\hline \multicolumn{1}{|c|}{ SUBSTÂNCIA } & $\begin{array}{c}\text { MERCADO LOCAL } \\
\text { RONDÔNIA }\end{array}$ & $\begin{array}{c}\text { MERCADO INTERNO } \\
\text { BRASILEIRO }\end{array}$ & MERCADO EXTERNO \\
\hline Água Mineral & & & \\
\hline Areia & & & \\
\hline Argila & & & \\
\hline Cascalho & & & \\
\hline Cassiterita & & & \\
\hline Columbita & & & \\
\hline Gemas & & & \\
\hline IImenita & & & \\
\hline Ouro & & & \\
\hline Pedra Britada & & & \\
\hline
\end{tabular}

Fonte: Autor

Os detentores de títulos minerários de maior porte têm mais aplicabilidade de técnicas administrativas e planejamento para desenvolvimento no médio e longo prazo. Verificou-se em trabalhos realizados que uma empresa produtora de brita, além das vendas efetuadas aos consumidores locais entrou no ramo da construção civil e houve um crescimento satisfatório do faturamento bruto.

No entanto, a falta de uma estratégia para o médio e longo prazo inibiu a trajetória de crescimento que poderia ser ainda maior, de forma que a própria equipe de fiscalização da ANM informou ao minerador que a empresa poderia alavancar seu crescimento, para isso teria que buscar uma consultoria, pois havia infra-estrutura suficiente e um mercado favorável ao desenvolvimento. Para Roberts:

A estratégia é um mecanismo controlador que ajuda a ordenar quais das muitas oportunidades a empresa deverá buscar e quais ela deverá ignorar. A estratégia também permite que as pessoas na organização tomem decisão sem precisar se estender em longas discussões e debates. Além disso, a estratégia pode contribuir para a motivação, 
definindo limites e objetivos explícitos para escolhas (ROBERTS, 2005, p.10).

No caso relatado os fatores impeditivos de um maior crescimento empresarial estão na falta de uma administração inovadora que formule um planejamento estratégico e a implementação condizente de técnicas contábeis e fiscais, desse modo dois pontos chamaram atenção, não havia um plano de prioridades para reinvestimentos dos lucros e a falta de uma gestão eficiente da contabilidade empresarial.

As forças econômicas do mercado apontam o cenário positivo para o investimento da empresa em direção ao crescimento, no entanto a gestão da firma ignora a oportunidade apresentada através da falta de conhecimento do empresário minerador e dos funcionários da organização, de acordo com Drucker:

A empresa privada é criada e dirigida por pessoas e não por forças econômicas. As forças econômicas fixam os limites à atuação da direção. Criam oportunidades para em seu interior agir, mas não determinam por si mesmas o que a empresa seja ou faça (DRUCKER, 1998, p. 55).

Em análise sistêmica da condução dos negócios no mercado local de areia, constatouse que os mineradores se orientam em vários sentidos, não há um plano organizado para buscar um aumento da produtividade da extração desse agregado mineral, falta o planejamento estratégico, percebe-se que não há critérios pré-definidos há apenas o enfrentamento dos desafios do ambiente comercial.

As determinações empresariais dessas empresas são realizadas sem um plano de futuro, ou seja, buscando resolver apenas as adversidades momentâneas do entorno da firma, infere-se que em havendo um planejamento estratégico as turbulências e incertezas teriam medidas mais efetivas com mais conhecimento para a tomada de decisão.

Desse modo, a visão administrativa dos mineradores que participam do mercado local, é buscar no curto prazo meio eficiente para aumentar a lucratividade dos recursos financeiros investidos, pois estas firmas não têm um planejamento de médio e longo prazo. 


\subsection{METODOLOGIA UTILIZADA NO TRABALHO}

Nesta investigação utilizou-se o enfoque qualitativo e o estudo descritivo, foi uma pesquisa bibliográfica onde se estudou o setor de mineração dos municípios de Ariquemes, Campo Novo de Rondônia, Itapuã do Oeste, Monte Negro e Porto Velho, os instrumentos de coleta de dados do estudo foram: livros, revistas, sites da Internet, artigos e a legislação correlata. Este trabalho está classificado como pesquisa bibliográfica, pois o estudo foi realizado tendo como fonte os trabalhos já publicados, objetivando alcançar os objetivos e explicar o problema, segundo Cervo e Bervian:

A pesquisa bibliográfica procura explicar um problema a partir de referências teóricas publicadas em artigos, livros, dissertações e teses. Pode ser realizada independentemente ou como parte da pesquisa descritiva ou experimental. Em ambos os casos, busca-se conhecer e analisar as condições culturais ou científica do passado sobre determinado assunto, tema ou problema (CERVO E BERVIAN, 2007, p. $60)$.

Aliado a pesquisa de dados utilizados pelos instrumentos de coletas mencionados, utilizaram-se também informações do sistema da intranet da Agência Nacional de Mineração, principalmente para buscar informações agregadas do RAL - Relatório Anual de Lavra.

\section{CONSIDERAÇÕES FINAIS}

Constatou-se que as substâncias minerais extraídas nos principais municípios produtores de minério de estanho do Estado de Rondônia: Ariquemes, Campo Novo, Itapuã do Oeste, Monte Negro e Porto Velho, atingem diversos centros consumidores, inter-relacionando com o mercado local do Estado de Rondônia, interno brasileiro e externo.

Comprovou-se que a Compensação Financeira pela Exploração de Recursos Minerais é empregada pelo poder público, como forma compensar os Estados e Municípios pelos danos ambientais e sociais ocasionados pela exploração mineral no âmbito dos seus territórios, sendo distribuída com $60 \%$ para os Municípios de origem da 
produção, 15\% para os Estados onde ocorrer a produção, e 15\% para os Municípios afetados pela atividade de mineração.

Observou-se que considerando a produção de minérios de cada um dos municípios pesquisados nesse trabalho, comparando-a com o Produto Interno Bruto de cada municipalidade, verifica-se que Campo Novo de Rondônia é o município onde se obtém o maior valor percentual, perfazendo 43,95 por cento na relação do montante de vendas dos minérios e o PIB municipal.

Apurou-se que a indústria de mineração é uma importante fonte de emprego, utiliza uma parcela considerável da população economicamente ativa dos municípios estaníferos de Rondônia.

Verificou-se que os mineradores que organizaram profissionalmente suas empresas aplicam técnicas empresariais e planejamento para desenvolvimento no médio e longo prazo, no entanto existe também a visão administrativa de lucratividade apenas de curto prazo principalmente entre os produtores que atuam no mercado local.

\section{REFERÊNCIAS}

AGÊNCIA NACIONAL DE MINERAÇÃO 2020: Disponível em $<$ https://anmlegis.datalegis.inf.br/action/ActionDatalegis.php?acao=apresentacao\&co d_menu=7270\&cod_modulo=431>Acesso em: 25 set. 2020.

CADASTRO GERAL DE EMPREGADOS E DESEMPREGADOS. Disponível em: $<$ http://bi.mte.gov.br/bgcaged/caged_perfil_municipio/index.php> Acesso em: 20 set. 2020.

CARVALHO NETO, Deolindo. Implicações Socioeconômicas e Ambientais Resultantes da Extração de Cassiterita, Ouro e Diamante em Rondônia, Porto Velho: União das Escolas Superiores de Rondônia, 2004.

CERVO, Amado L; BERVIAN, Pedro A; DA SILVA, Roberto. Metodologia científica. 6. ed. São Paulo: Pearson Prentice Hall, 2007. 
DECRETO-LEI

№

$5.812 / 43$.

Disponível

em:

<http://www.planalto.gov.br/ccivil_03/decreto-lei/1937-1946/Del5812.htm>

Acesso em: 20 jun. 2013.

DRUCKER, Peter Ferdinand. A Prática da Administração de Empresas. São Paulo: Thomson, 1998.

IBGE, Disponível em: <https://www.ibge.gov.br/cidades-e-estados/ro/.html> Acesso em: 18 set. 2020.

LEI COMPLEMENTAR № 41/81. Disponível em: <http://www.planalto.gov.br/ccivil_03/leis/lcp/lcp41.htm> Acesso em: 20 jun. 2013.

LEI № 2.731/56. Disponível em: <http://www.planalto.gov.br/ccivil_03/leis/19501969/L2731.htm> Acesso em: 20 jun. 2013.

Núcleo de Tecnologia Educacional de Ji-paraná. Disponível em: <http://ntejipa.zip.net/> Acesso em: 20 jun. 2013.

OLIVEIRA, Ovídio Amélio de. História Desenvolvimento e Colonização do Estado de Rondônia. 5ª ed. Porto Velho: Dinâmica Editora e Distribuidora Ltda, 2004.

PINDYCK, Robert S. e RUBINFELD, Daniel L. Microeconomia. 6aㅡ Ed. São Paulo: Pearson Prentice Hall, 2006.

ROBERTS, John. Teoria das Organizações: redesenho organizacional para o crescimento e desempenho máximos, (Trad. Ana Beatriz Tavares e Daniela Lacerda). Rio de Janeiro: Elsevier, 2005.

ROSSETI, José Paschoal. Introdução à Microeconomia. 19ª Ed. São Paulo: editora Atlas. 2001.

Enviado: Outubro, 2020.

Aprovado: Outubro, 2020. 